\title{
PAVLOVSKY E SORRE: DUAS IMPORTANTES CONTRIBUIÇÕES À GEOGRAFIA MÉDICA
}

\author{
PAVLOVSKY E SORRE: TWO IMPORTANTS CONTRIBUTIONS TO \\ MEDICAL GEOGRAPHY
}

\section{PAVLOVSKY E SORRE: DEUX CONTRIBUTIONS IMPORTANTES À LA GÉOGRAPHIE MÉDICALE}

\section{Renato Guedes Vieites}

Universidade do Estado do Rio de Janeiro. Programa de Pós-Graduação em Geografia. Rua São Francisco Xavier, 524. Bloco D, sala 4033D. Rio de Janeiro - RJ.

E-mail: renatoguedesvieites@hotmail.com

Inês Aguiar de Freitas

Universidade do Estado do Rio de Janeiro. Programa de Pós-Graduação em Geografia. Rua São Francisco Xavier, 524. Bloco D, sala 4033D. Rio de Janeiro - RJ.

E-mail: freitasines@bol.com.br

\begin{abstract}
Resumo
Uma análise histórica dos primeiros conhecimentos em Geografia demonstra que é antiga a associação entre esta e a Medicina, podendo ser identificada desde a Antiguidade a menção ao tratamento de temas relacionando saúde, ambiente e o espaço. No momento em que a geografia transforma-se em ciência, no fim do século XIX, os contatos iniciais entre a Geografia e a Epidemiologia levaram aos estudos em Geografia Médica, relacionados à descrição minuciosa da distribuição regional das doenças. No século XX, os conceitos de "foco natural de doença”, do parasitologista Evgeny Pavlovsky e de "complexo patogênico", do geógrafo francês Maximillien Sorre aprofundaram tais estudos. Nosso objetivo principal é analisar a contribuição que estes dois cientistas/pensadores, através dos conceitos que criaram, trouxeram aos estudos em Geografia Médica. Neste estudo, através do resgate e da correlação entre os principais conceitos de Pavlovsky e de Sorre, queremos destacar sua importância como instrumentos de análise e integração entre a geografia e a epidemiologia, recuperando, ainda, uma das mais novas “evoluções” da Geografia Médica: a Saúde Ambiental.
\end{abstract}

Palavras-chave: Geografia Médica - Epidemiologia - Focos Naturais de Doenças Complexo Patogênico - Pensamento geográfico. 


\begin{abstract}
A historical analysis of the first geographic knowledge shows that the association between Geography and Medicine occurs since ancient times concernig the interface among subjects as health, environment and space. In the late nineteenth century, when Geography achieved status of an academic branch of science, its former approaches to Epidemiology leaded to Medical Geography studies, which consisted on a detailed description of diseases and its regional distribution. In the twentieth century, the conceptions of "Natural Focality of Transmissive Diseases", of parasitologist Evgeny Pavlovsky and "Patogenic Complex", of the French geographer Maximillien Sorre. In this research, our main aim is to analyze the contributions that both scientists/thinkers brought to Medical Geography by recalling and correlating their formulations, emphasizing the instrumental importance of their concepts for analisys, as well as the connection between Geography and Epidemiology they established. Regarding also subjects related to a recently advancing area in Medical Geography: the studies on Environmental Health.
\end{abstract}

Key words: Medical Geography - Epidemiology - Natural Focality of Transmissive Diseases - Patogenic Complex- Georaphical Thought.

\title{
Résumé
}

Une analyse historique des premières connaissances em géographie montre que l'association entre la géographie et la médecine se produit depuis les temps anciens en ce qui concerne l'interface entre des sujets comme la santé, l'environnement et l'espace. À la fin du XIXeme siècle, lorsque la géographie atteint un status de science, les anciennes méthodes de l'épidémiologie conduit à des études médicales em géographie, qui consistait d'une description détaillée des maladies et de sa répartition régionale. $\mathrm{Au}$ XXeme siècle, les notions de "Focus naturel de Maladies Transmissives", du parasitologue Evgeny Pavlovsky, et de "Complexes patogeniques", du géographe français Maximillien Sorre ont approfondi ce genre d'études. Dans cette recherche, notre objectif principal est d'analyser la contribution que les deux scientifiques / penseurs ont éméner aux études en géographie en rappelant les études médicaux, en soulignant l'importance de leur rôle de concepts d'analyses, ainsi que le lien entre la géographie et l'épidémiologie qu'íls ont établie, en ce qui concerne également des sujets relatifs à la promotion récente d'un domaine dans la Géographie médicale: les études sur la santé environnementale.

Mots clés: Géographie médicale - Epidémiologie - Focus naturel de Maladies Transmissives - Complexe Patogenique - Pensée Géographique.

\section{Introdução}

Estudos em história do pensamento geográfico demonstram a antiga associação entre a Geografia e a Medicina, podendo ser identificada desde a Antiguidade a menção ao tratamento de temas relacionados ao que mais tarde seria chamado de Geografia Médica, tais como: as correlações entre as diferentes regiões, o 
meio ambiente, o clima (especialmente) e a saúde dos seres humanos (GLACKEN, 1990).

Este trabalho terá, então, como objetivo principal estudar a antiga relação entre a Geografia e a Medicina e terá ainda, como objetivos secundários, derivados deste primeiro e tornando-o realizável:

1- Definir Geografia Médica (ou da Saúde ${ }^{1}$ ), verificando como este ramo da Geografia sofreu alterações ao longo do tempo.

2- Analisar as contribuições de autores como: Evgeny Pavlovsky, Maximillien Sorre e, mais recentemente, dos brasileiros Samuel Pessoa e Luís Jacintho da Silva, assim como os autores que hoje tratam da chamada "Saúde Ambiental".

3- Relacionar os trabalhos de epidemiologia com os de geografia médica, a fim de evidenciar como estas duas disciplinas contribuíram para a contribuição da geografia da saúde.

A primeira parte de nosso trabalho tratará dos antecedentes da geografia médica, relacionando-a à filosofia pré-socrática, à physis e à origem do pensamento hipocrático. É importante verificar como as condições religiosas, filosóficas e comportamentais do povo grego permitiram que o mesmo tivesse uma visão diferenciada do processo saúde/doença, o que concedeu um enorme impulso para que a medicina lá surgisse.

$\mathrm{Na}$ segunda parte, trataremos dos contatos iniciais entre a Geografia Científica e a Epidemiologia que levaram aos estudos de Geografia Médica relacionados à distribuição regional das doenças, com vasta utilização de recursos cartográficos. Veremos que os estudos pioneiros em Geografia Médica, impregnados com o viés positivista, fizeram a vinculação entre áreas endêmicas de doenças com determinadas características culturais, raciais e climáticas, relacionando ambientes e grupos populacionais sob a égide do determinismo ambiental.

A terceira parte tratará da contribuição do parasitologista soviético Evgeny Pavlovsky, com a sua teoria dos focos naturais de doenças transmissíveis, segundo a qual "um foco natural de doença” existe quando há um clima, vegetação, solo específico

\footnotetext{
${ }^{1}$ Alguns autores tratam os dois termos como sinônimos. No entanto, Oliveira (1993) destaca que a Geografia da Saúde, proposta pelo Congresso de Moscou (1976), passou unir os conteúdos de Geografia Médica e a dos Serviços de Saúde. Aqui optamos pela utilização do termo Geografia Médica.
} 
e micro-clima favorável nos lugares onde vivem vetores, doadores e recipientes de infecção.

Na quarta parte, é ressaltada a contribuição de Maximillien Sorre e a importância de sua teoria dos complexos patogênicos, segundo os quais este geógrafo francês analisou uma vasta gama de doenças infecciosas e parasitárias.

Nossas últimas considerações versam sobre a passagem da Geografia Médica à Saúde Ambiental, na qual se revaloriza o caráter contemplativo do saber, típico do pensamento pré-moderno e especialmente da filosofia pré-socrática. Um saber compreensivo que não dissocia, mas que integra o conhecimento às dimensões ética e estética da realidade, o pensamento e a razão, à sensibilidade.

\section{Antecedentes da Geografia Médica: a filosofia pré-socrática, physis e origem do} pensamento hipocrático.

O fato de a Grécia ter sido o lugar em que apareceram as tentativas pioneiras de se explicar racionalmente as doenças, vendo-as como resultado do desequilíbrio na natureza, não foi por acaso. Essa característica da medicina grega é compatível com o pensamento grego de se analisar o comportamento humano, além das atividades práticas (do dia-a-dia) ou religiosas, assumindo um comportamento propriamente filosófico e desenvolvendo uma autonomia acentuada da postura racional diante do mundo e dos fenômenos. Essa autonomia não negava o pensamento religioso, visto que a própria característica da religião, na Grécia, condicionava esse comportamento, pois os deuses gregos não eram entidades sobrenaturais, mas sim partes integrantes da natureza. A atividade racional afirmou-se com intensidade crescente na Grécia, tendo atingido, com a filosofia pré-socrática, um primeiro momento de maturidade.

A origem da medicina grega reside nessa concepção filosófica, oriunda das colônias gregas, nos séculos VI e V a.C. Baseada na idéia de physis ${ }^{2}$, nasce a idéia da dinâmica de corpo e de doença da medicina hipocrática. Dela, provinha tudo o que era, o que é e o que será, ou seja, Sol, Terra, astros, árvores, homens, animais e os próprios deuses.

\footnotetext{
${ }^{2}$ Entre muito significados, physis significa produzir, crescer, desenvolver-se, "indica aquilo que por si brota, se abre, emerge, o desabrochar que surge de si próprio e se manifesta neste desdobramento, pondose no manifesto" (BORNHEIM,1997, p.12).
} 
Na physis, não existia contraposição entre o natural, psíquico e social, pois todas estas dimensões pertenceriam a ela, até mesmo os deuses. Não havia distinção entre natureza animada e inanimada. Na physis, atuava um princípio inteligente, reconhecido como espírito, pensamento ou logos.

Os elementos que compunham a physis formariam harmonicamente todas as coisas, por meio de forças vivas de reunião (amor) e de dispersão (discórdia). A harmonia e o equilíbrio constituintes da natureza seriam resultados da coexistência dessas forças paradoxais que tenderiam, uma, à agregação, e outra, à desagregação; uma, à separação, e outra, à indiferenciação.

Não seria, portanto, o homem que conseguiria unificar o que está disperso, a partir de um processo lógico. Mesmo reconhecendo a distinção entre homem e mundo, a relação entre eles foi pensada sem distanciá-los e dissociá-los um do outro. Por meio da physis, o homem deveria entender que o mundo era uma totalidade e que não havia sentido em pensar em dualidades, tais como: corpo e alma, mundo inteligível e mundo sensível, razão e emoção. Para ser compreendida, a natureza deveria ser apreendida. O homem poderia observá-la e contemplá-la, mas não dominá-la (BOHADANA,1988).

A physis não pode ser confundida com uma espécie de naturalismo que equivaleria a uma idéia de natureza tal como aquela que constituía o objeto das ciências da natureza, pensada como algo que pode ser dominado e canalizado pelo homem, em termos de técnica (CZERESNIA, 2001).

Como se observa, a concepção de natureza que prevaleceu na emergência das ciências naturais, a partir dos séculos XVI e XVII, era radicalmente distinta e muito mais restrita, conformando a experiência de natureza do homem moderno de modo muito diferente daquele estabelecido no conceito de physis.

A importância da filosofia pré-socrática fica clara no pensamento de Alcmeón, o médico de Crotona, como uma das expressões mais claras de uma idéia physiológica da medicina.

Alcmeón afirma que a saúde sustenta-se pelo equilíbrio das forças (isonomia tõn dynámeõn): o úmido e o seco, o frio e o quente, o amargo e o doce, e as demais. O predomínio (monarkhía) de uma delas é causa de doença. Pois tal predomínio de uma das duas é pernicioso. Essa é a característica básica que orienta a obra de Hipócrates e dos outros autores do Corpus Hippocraticum. Na concepção hipocrática, o corpo humano e tudo aquilo que o circunda - que, em conjunto, constituem a physis - 
eram pensados por meio da composição dos elementos ar, terra, água e fogo, e pelas qualidades de frio, quente, seco e úmido. Corpo e espaço eram compreendidos a partir desses elementos e qualidades. Daí, a importância de estudar o meio ambiente e o clima das diferentes regiões da Terra para se compreender a sua influência (melhor dizendo, a sua marca) sobre o homem.

\section{A gênese da Geografia Médica}

A associação entre Geografia e a Medicina é antiga, podendo esta ser identificada desde a Antiguidade Clássica, em que a descrição dos lugares e das sociedades humanas nelas instaladas está presente, por exemplo, na História, de Heródoto. Também na Idade Antiga, a obra Dos Ares, das Águas e dos Lugares, de Hipócrates $^{3}$ (480 a.C.) muito provavelmente foi pioneira no tratamento de temas relacionados à Geografia da Saúde (GLACKEN, 1990).

De acordo com Glacken (1990, p. 87), esta obra de Hipócrates trata de como a constituição do corpo se alteraria de modo integrado às mudanças que ocorrem na constituição da natureza. É com essa fundamentação que, por exemplo, o tratado Dos Ares, das Águas e dos Lugares descrevia a influência das mudanças sazonais, dos climas e dos ventos sobre o corpo humano e suas doenças.

As estações do ano, por exemplo, possuíam qualidades que lhes eram características. Sob a influência dessas qualidades, os humores corporais iriam variar em composição, favorecendo ou não o aparecimento de determinadas doenças. Era possível conhecer as mudanças que iriam ocorrer e como elas poderiam transformar o corpo, ao modificar a quantidade e a qualidade dos seus humores. Mas não era possível intervir no sentido de alterar essas predisposições, podendo-se apenas tentar evitar certas circunstâncias (CZERESNIA, 2001).

Os trabalhos iniciais sobre Geografia Médica fizeram a vinculação entre áreas endêmicas de doenças com determinadas características culturais, raciais e climáticas, relacionando ambientes e grupos populacionais de forma “determinista”, em virtude da indistinção entre as variáveis de saúde, seus determinantes, bem como seus

\footnotetext{
${ }^{3}$ Hipócrates - é apontado como o Pai da Medicina. Desta forma, pode-se afirmar que a Geografia Médica ou da Saúde surgiu com a própria Medicina.
} 
contornos sócio-econômicos, pelos quais foram atribuídos vários preconceitos étnicos, culturais e ambientais a esse campo científico que surgia (LACAZ et al. 1972).

Durante o século XIX, sob o domínio do positivismo, a relação entre a geografia e a epidemiologia gerou ensaios pioneiros da geografia médica, produzindo descrições minuciosas da distribuição regional de doenças, quando se passou a empregar amplamente recursos cartográficos.

Ainda na segunda metade do século XIX, começaram a ser produzidos os tratados de climatologia médica, muito utilizados por Maximillien Sorre na elaboração de seus trabalhos, pois se tratavam de estudos elaborados com maior precisão científica que procuravam correlacionar a ocorrência das doenças, direta ou indiretamente, com aspectos da geografia física, especialmente com as variações climáticas (FERREIRA, 1991).

Foi somente há pouco mais de um século que os epidemiologistas e outros cientistas da área médica começaram a explorar o potencial de informações contidos nos mapas para fins de criação de padrões espaciais de doenças, visto que a geografia, apenas no início do século XIX, passa a usufruir de certa unidade temática e metodológica (Op. Cit, 1972).

Apesar de sua longa história, a Geografia Médica só foi reconhecida oficialmente no Congresso Internacional de Lisboa, em 1949, sendo que este reconhecimento pode ter sido em muito ajudado pela definição de saúde apresentada em 1948, pela Organização Mundial de Saúde (OMS), segundo a qual, saúde "é o estado de completo bem-estar físico, psíquico e social e não meramente a ausência de enfermidades". (ESTEVES, 1996 apud EHARALDT, 1999, p.15).

Durante o século XX, pode-se destacar dois sistemas teórico-conceituais e metodológicos que traduzem a interface entre a geografia e a epidemiologia, através do conceito do foco natural de doenças, de Evgeny Pavlovsky e o conceito de complexo patogênico, de Maximillien Sorre (CZERESNIA; RIBEIRO, 2000).

\section{Evgeny Pavlovsky e a Teoria dos Focos Naturais de Doenças}


O parasitologista Evgeny Nikanorovich Pavlovsky ${ }^{4}$ (1884-1965) trabalhou no Instituto de Zoologia da Academia de Ciências da ex-União Soviética, de 1930 até 1965, com um vasto conhecimento em todas as disciplinas zoológicas, além de conhecimentos em geografia e medicina, demonstrando atenção particular à parasitologia.

Realizou, na década de 1930, uma das mais importantes elaborações teóricas do conceito de espaço geográfico vinculado ao estudo de doenças transmissíveis, criando a teoria do foco natural de doenças transmissíveis.

Esta teoria serviria de base para as investigações "sobre o impacto epidemiológico de corrente da ocupação pelo homem de extensas porções semidesertas do território soviético". (FERREIRA, 1991). Seu conceito de foco natural expressa uma apreensão espacial que integra o conhecimento das doenças transmissíveis com a geografia e a ecologia. Para Pavlovsky,

Um foco natural de doença existe quando há um clima, vegetação, solo específicos e micro-clima favorável nos lugares onde vivem vetores, doadores e recipientes de infecção. Em outras palavras, um foco natural de doenças é relacionado a uma paisagem geográfica específica, tais como a taiga com uma certa composição botânica, um quente deserto de areia, uma estepe etc., isto é, uma biogeocoenosis. O homem torna-se vítima de uma doença animal com foco natural somente quando permanece no território destes focos naturais em uma estação do ano definida e é atacado como uma presa por vetores que lhe sugam o sangue (s/d:19 apud CZERESNIA; RIBEIRO, 2000, p.5).

O conceito de foco natural é, por conseguinte, aplicado a ambientes que apresentam condições favoráveis à circulação de agentes, independentemente da presença e da ação humanas. Pode ocorrer em paisagens geográficas diversas, contando que haja uma interação entre biótipos específicos.

A definição de foco natural circunscreve-se a doenças transmitidas através de vetores, não se referindo ao estudo de doenças que, mesmo apresentando um agente etiológico definido, propagam-se através do contato direto ou mesmo pela inalação de ar contaminado, como difteria, sarampo, escarlatina e doenças respiratórias.

\footnotetext{
${ }^{4}$ Pavlovsky foi, por duas vezes, o vencedor do Prêmio do Estado (1941 e 1950) e do Prêmio Lênin (1965). Também foi presidente da União da Sociedade Entomológica da Academia de Ciências da URSS (1931-1965) e da Sociedade Geográfica (1952-1965) daquela academia.
} 
Pavlovsky também desenvolveu o conceito de foco antropúrgico ${ }^{5}$, que defendia a idéia da transformação do espaço de circulação de agentes de doença pela ação humana (FERREIRA, 1991). Entretanto, este conceito refere-se apenas à transformação inicial dos focos naturais não apresentando elementos suficientes para o estudo das doenças transmissíveis em situações onde a dinâmica de modificação do espaço pelo homem ocorreu de forma mais ampliada e acelerada (CZERESNIA; RIBEIRO, 2000).

O trabalho de Pavlovsky teve grande influência no Brasil, com Samuel Pessoa e Luís Jacintho da Silva. O parasitologista Samuel Pessoa inspirou-se especialmente nos trabalhos de Pavlovsky, criando uma escola de estudos em geografia médica no Brasil, no contexto da chamada medicina tropical. Estudou as endemias prevalentes no Brasil, também, e especialmente, as transmitidas através de vetores, como esquistossomose, doença de Chagas, filariose, malária etc.

Uma reelaboração das idéias de Pavlovsky que também merece destaque foi realizada por Luís Jacintho da Silva. Este autor fez uma análise bastante completa sobre a evolução da doença de Chagas no Estado de São Paulo, baseada numa releitura crítica do esquema conceitual de Pavlovsky, no âmbito da geografia marxista, inspirado em Milton Santos. O autor faz uma radicalização da noção de foco antropúrgico (originado pela ação humana sobre a natureza), destacando a utilidade deste conceito para expressar a determinação social das formas de ocupação do espaço e da distribuição das doenças neste espaço transformado pela ação humana. Segundo o mesmo autor, a inspiração ecológica de Pavlovsky é, portanto, reformulada em termos de relação homem-meio, cuja análise recai no âmbito das ciências econômicas e sociais.(FERREIRA, 1991).

\section{Maximillien Sorre e os Complexos Patogênicos}

\footnotetext{
${ }^{5}$ A existência de qualquer doença transmissível depende do trânsito contínuo de seu agente causal, do corpo do animal doador (animal doente, portador assintomático, hospedeiro do parasita) para o corpo do vetor. Essa transmissão geralmente ocorre quando o vetor suga o sangue do doador e subseqüentemente transmite o agente causal para o receptor animal, freqüentemente, quando suga seu sangue também; o receptor infectado pode por sua vez, tornar-se um doador para outro grupo de vetores, etc. Desta maneira, ocorre, como dizemos, a circulação (PAVLOVSKY, s/d:18 apud CZERESNIA; RIBEIRO, 2000, p. 6).
} 
O géografo francês Maximillien (Max) Sorre ${ }^{6}$ (1880-1962), foi seguidor da Escola Possibilista de Geografia e trabalhou no sentido de integrar os estudos de Geografia Física aos de Geografia Humana. Sorre possuía a preocupação teórica de fornecer uma base conceitual à geografia médica que possibilitasse estudos de natureza interdisciplinar. Daí a importância de, permanentemente, analisar a sua contribuição geográfica aos estudos em epidemiologia e medicina (SORRE, 1982).

Max Sorre foi além da abordagem de Pavlovsky ao trabalhar a importância da ação humana na formação e dinâmica de complexos patogênicos. O conceito de complexo patogênico ampliou o poder analítico e explicativo de uma concepção antes praticamente restrita à descrição do meio físico.Em sua obra Les fondements de la geógraphie humaine, Sorre realiza um dos empreendimentos intelectuais mais importantes, estabelecendo inúmeros pontos de contato entre a geografia e as ciências sociais e biológicas, contato que marcaria sua obra geográfica.

A teoria do complexo patogênico, desenvolvida por Sorre, permitiu abordar uma vasta quantidade de doenças infecciosas e parasitárias, enquanto que a teoria de Pavlovsky se limita ao estudo de enfermidades de animais transmissíveis ao homem, que possuiriam seu foco natural - um reservatório silvestre - em um meio "intocado" pelo homem (ou, no mínimo, onde este fator não seria levado em conta). De acordo com Sorre (1982), os complexos patogênicos expressam equilíbrios em eterna transformação e sua evolução se traduz em mudanças nas áreas das doenças infecciosas.

Ao assumir a ecologia como eixo central, o conceito de espaço que Sorre utiliza é, por um lado, o mesmo que se formula através da biologia: as relações entre um meio externo que varia e um meio interno que necessita adaptar-se para manter suas constantes fisiológicas. Por outro lado, o autor explicita que, ao se tratar de seres humanos, o conceito de meio deve enriquecer-se e incluir também o ambiente produzido pelo homem, marcando a principal diferença entre a sua concepção daquela de Pavlovsky (VIEITES, 2003).

Refere-se, assim, ao conceito de gênero de vida que considera, na mais pura tradição lablachiana, "o conjunto da organização social humana em seus aspectos materiais e espirituais". É compreendido como combinação de técnicas, cujo uso e

\footnotetext{
${ }^{6}$ Em sua tese de doutoramento, Max Sorre utilizou o enfoque da biogeografia e versou sobre Os Pirineus Mediterrâneos (1913). Outras de suas obras: Os Fundamentos da Geografia Humana (4 vols., 19431952) e O Homem na Terra (1962), que dão continuidade às reflexões de Vidal de La Blache.
} 
desenvolvimento adaptam-se às diferentes condições geográficas onde se inserem grupos humanos. Transforma-se com as necessidades e atividades dos grupos, assegurando sua sobrevivência (SORRE, 1984).

A constituição do gênero de vida de grupos humanos, além de influenciar a formação psicológica dos indivíduos, pode modelar a própria aparência física destes.

A riqueza do conceito de gênero de vida, contudo, não se esgota totalmente no conceito de complexo patogênico, que também busca integrar as dimensões física, químicas, biológicas, econômicas, sociais e culturais.

O conceito de complexo patogênico tem ainda como objetivo explicitar uma compreensão sintética (GADELHA, 1995). Este conceito trabalha com uma perspectiva dinâmica, referindo-se ao conjunto de circunstâncias que predispõem um lugar, em determinado período, ao surgimento de doenças (CZERESNIA; RIBEIRO, 2000).

Porém, apesar dessa intenção de síntese (característica dos geógrafos), Sorre estuda os complexos patogênicos, classificando-os de acordo com agentes microbiológicos que definem doenças específicas, e coloca seu trabalho sob uma perspectiva analítica:

(...) A interdependência dos organismos postos em jogo na produção de uma mesma doença infecciosa permite inferir uma unidade biológica de ordem superior: o complexo patogênico. Compreende, além do homem e do agente causal da doença, seus vetores e todos os seres que condicionam ou comprometem a sua existência (...) (SORRE, 1951, apud FERREIRA, 1991, p. 306).

Max Sorre nomeou os complexos patogênicos de acordo com as doenças a que se referiam. Desta forma, existem o complexo malárico, da doença do sono, da peste etc., ou seja, realizou uma espécie de "regionalização" desses complexos. Em sua abordagem ecológica, analisou a ação antrópica de alteração do meio ambiente, relacionando-a com o seu possível impacto epidemiológico. Subordinou (e limitou), porém, a atividade humana no sentido da modificação do ambiente, à sua perspectiva ecológica, "naturalizando” o conceito de gênero de vida.

O conceito de complexo patogênico apesar (e talvez por isso mesmo) de se inscrever em uma perspectiva "naturalista" da geografia (e não em uma perspectiva "social" de nossa ciência) permitiu, no entanto, que Sorre demonstrasse que múltiplos aspectos materiais e imateriais constituem o espaço, envolvendo praticamente todas as 
dimensões da existência humana do utilizar o conceito de gênero de vida (CZERESNIA; RIBEIRO, 2000). O conceito de complexo patogênico de Sorre, contudo, não é suficiente para explicar grande parte dos problemas de saúde pública na sociedade contemporânea. Estes demandam novos discursos e abordagens que permitam aprofundar a perspectiva multi ou transdisciplinar. Afinal, o mundo é muito mais complexo do que um conjunto de regiões, onde se juntaram várias possibilidades humanas. Talvez pela sua abordagem ecológica ter sido considerada excessivamente (e, por isso, erroneamente) possibilista, o fato é que os complexos patogênicos não foram matéria de muitos debates e estudos, tais como o foram as idéias de Pavlovsky, especialmente no Brasil (Op. cit., 2000).

Trata-se de um lapso lamentável, pois como sustenta Ferreira (1991), a idéia dos grupos humanos organizando o espaço é bastante compatível com o conceito de complexo patogênico. Dever-se-ia sim, aprofundá-lo, aprimorá-lo e direcioná-lo em prol de uma geografia médica que desse conta também dos problemas sócio-ambientais.

\section{Considerações finais: da Geografia Médica à Saúde Ambiental}

A crise do mundo contemporâneo põe em xeque os valores que constituíram a racionalidade moderna: a concepção de que existe um mundo objetivo, independente do sujeito que o analisa, passível de ser conhecido e dominado pela razão; a construção de um conhecimento sistemático fundado na observação e na experimentação, no desvelamento das leis que determinam o movimento da natureza (VAITSMAN,1995); a instituição do método analítico que, pelo distanciamento, a dissociação e a fragmentação, viabiliza a construção de um conceito, objeto, claro, preciso e neutro.

O interesse pelo pensamento pré-socrático tornou-se crescente e ganhou uma intensidade especial no contexto da crise da modernidade, quando se ampliaram as interrogações quanto à lógica da ciência moderna. A redescoberta da filosofia présocrática situou os critérios de sua interpretação em novas bases. Esse movimento trouxe também, e conseqüentemente, novos elementos para a interpretação da idéia de constituição em epidemiologia.

Neste contexto, há uma redescoberta da lógica pré-socrática, que privilegia a não separação ou a não-fragmentação do conhecimento. Retoma-se como valor uma concepção de natureza que não se dissocie da construção humana. Questionam-se as 
dualidades clássicas como corpo e alma, razão e emoção, sujeito e objeto, natureza e cultura.

Além disso, revaloriza-se o caráter holístico do saber, típico do pensamento pré-moderno e especialmente da filosofia pré-socrática. Como dissemos anteriormente, um saber compreensivo que não dissocie, mas que una, integre o conhecimento às dimensões ética e estética da realidade, o pensamento e a razão à sensibilidade. $\mathrm{O}$ objetivo não é a verdade, mas a felicidade e a virtude, ou seja, a sabedoria para uma vida melhor.

O que se pretende enfatizar é a construção de intervenções vinculadas aos condicionantes do adoecimento, e não a uma ou a outra doença em si mesmas. Essa 'nova' concepção é mais uma das abordagens que recuperam, em outras bases, o tratamento das epidemias a partir de um conjunto integrado de circunstâncias, expressa em situações particulares, e não a partir da análise genérica de doenças específicas. O meio, o ambiente ganha, aqui, uma outra dimensão (novamente) na explicação das doenças humanas, e, a Geografia Médica, novo impulso.

\section{Referências}

BARCELLOS, C. Organização Espacial, Saúde e Qualidade de Vida. In: Seminário Nacional Saúde E Ambiente No Processo De Desenvolvimento, 1, 2000, Rio de Janeiro. Série FIOCRUZ. Rio de Janeiro: Eventos Científicos, 2, pp. 27-35, 2000.

BIOGRAFIA SAMUEL PESSOA - Samuel Pessoa. Disponível na internet. http://www.camara.gov.br/aldorebelo/bonifacio/saude/biografia_sp.htm, 01 ago. 2005.

BOHADANA, E. Ver a vida, ver a morte: da filosofia e da linguagem. Rio de Janeiro: Tempo Brasileiro, 1988, 129 p.

BORNHEIM, G. Os filósofos pré-socráticos . São Paulo: Cultrix, 1997, 78 p.

BOUSQUAT, A.; COHN, A. A dimensão espacial nos estudos sobre saúde: uma trajetória histórica. História, Ciências, Saúde - Manguinhos. Rio de Janeiro, vol. 11, n. 3, p. 549-568, set./dez. 2004.

CARVALHO, A. I. Da saúde pública às políticas saudáveis: saúde e cidadania na pósmodernidade. Ciência \& Saúde Coletiva, vol. 1, n. 1, pp.104-21, 1996. 
CZERESNIA, D. Constituição epidêmica: velho e novo nas teorias e práticas da epidemiologia. História, Ciências, Saúde - Manguinhos. Rio de Janeiro, vol. 8, n. 2, p. 341-356, jul./ago. 2001.

Do Contágio à Transmissão: Ciência e Cultura na Gênese do Conhecimento Epidemiológico. Rio de Janeiro: Editora Fiocruz, 1997.

CZERESNIA, D.; RIBEIRO, A. M. O Conceito de Espaço em Epidemiologia: uma Interpretação Histórica e Epistemológica. Cadernos de Saúde Pública, Rio de Janeiro, vol. 16, n. 3, p. 595-617, jul./set. 2000.

EHARALDT, E. M. A Aplicabilidade da Geografia na Área Médica e Nutricional: O Custo da Cesta Básica X Renda Familiar e a Mortalidade Infantil. 87 f. Monografia (Graduação em Geografia) - Departamento de Geografia, UERJ, 1999.

FERREIRA, M. U. Epidemiologia e Geografia: O Complexo Patogênico de Marx Sorre. Cadernos de Saúde Pública, Rio de Janeiro, vol. 7, n. 3, p. 301-309, jul.set. 1991.

GADELHA, P. História de Doenças: Ponto de Encontros e de Dispersões. 120 f. Tese (Doutoramento em Saúde Pública) - Escola Nacional de Saúde Pública, Ensp/Fiocruz, 1995.

GLACKEN, C. J. Traces on the Rhodian Shore: Nature and Culture in western thought from ancient times to the end of the Eighteenth Century. Berkeley/London: University of California Press, 1990. 763 p.

LABORATORY OF PARASITOLOGY - Scientific School of E. N. Pavlovsky. Disponível na Internet http://www.zin.ru/labs/parasites/schoole.htm, 30. Mai 2005.

LACAZ, C. S.; BARUZZI, R. G.; SIQUEIRA Jr., W. Introdução à Geografia Médica do Brasil. São Paulo: EDUSP, 1972. 568p.

MEDRONHO, R. A. A Geografia do Dengue no Município no Rio de Janeiro: Uma Análise por Geoprocessamento. 133 f. Dissertação (Mestrado em Saúde Pública) Escola Nacional de Saúde Pública - Ensp/Fiocruz, 1993.

OLIVEIRA, A. Geografia de la Salud. Madri: Sintesis. (Coleção Espacios y Sociedades) Série Geral, n.26, 1993.

PESSOA, S. B. Ensaios Médico-Sociais. 2a ed., São Paulo: Cebes/Hucitec, 1978. 380 p.

RIBEIRO, M. F.; VIEITES, R. G. A Abordagem Geográfica Aplicada à Área da Saúde Pública: contribuições e reflexões. GeoUERJ, n. 12. Rio de Janeiro, Departamento de Geografia, 2002, p. 69-84.

SILVA, L. J, O conceito de espaço na epidemiologia das doenças infecciosas.

Cadernos de Saúde Pública, Rio de Janeiro, vol. 13, n.4, p.585-593, out./dez.

1997. 


\section{CATELIÊ GEOGRÁFICO

SORRE, M. A noção de gênero de vida e sua evolução. In: MEGALE, J. F. (Org.) Max Sorre: Geografia, pp. 99-123, Rio de Janeiro: Editora Ática, 1984.

- Los Fundamentos Biológicos de La Geografia Humana. Ensayo de una Ecologia del Hombre: Concusion. In: MENDOZA, J. G.; JIMÉNEZ, J. M.; CANTERO, N. O. (Org.) El pensamiento geográfico: Estudio interpretativo y antoloía de textos (De Humboldt a las tendencias radicales), pp. 267-274, Madrid: Alianza Editorial, 1982.

VAITSMAN, J. Subjetividade e paradigma de conhecimento. Boletim Técnico do SENAC, vol. 21, n. 2, maio-ago, 1995.

VIEITES, R.G. Interações Espaciais na Região Metropolitana do Estado do Rio de Janeiro com base na infra-estrutura ambulatorial e hospitalar, referentes ao ano 2000. 88 f. Monografia (Graduação em Geografia) - Instituto de Geografia/Depto. de Geografia, Universidade do Estado do Rio de Janeiro, 2003.

Interações Espaciais do Estado do Rio de Janeiro com base na infraestrutura ambulatorial e hospitalar, referentes ao ano 2003. $104 \mathrm{f}$. Monografia (Especialização em Políticas Territoriais no Estado do Rio de Janeiro) - Instituto de Geografia/Depto. de Geografia, Universidade do Estado do Rio de Janeiro, 2005.

Recebido para publicação outubro de 2007

Aprovado para publicação novembro de 2007 